\title{
Dolor torácico y disnea progresiva en varón joven
}

\author{
Borrego Jiménez P. ${ }^{1}$, Bartolomé Cela E. ${ }^{2}$, Molina López-Nava P. ${ }^{3}$, Carretero Quevedo A. ${ }^{4}$
}

Sanid. mil. 2012; 68 (2): 115-116; ISSN: 1887-8571

Varón de 45 años, con antecedente reciente de trombosis venosa profunda en miembros inferiores y consumo de suplementos dietéticos (alguno en límite de esteroides por vía oral y en cuya composición figuran sustancias consideradas pro-hormonas), y que acude a Urgencias por dolor torácico opresivo generalizado asociado a disnea progresiva. Refiere dolor costal izquierdo desde hace 7 días.

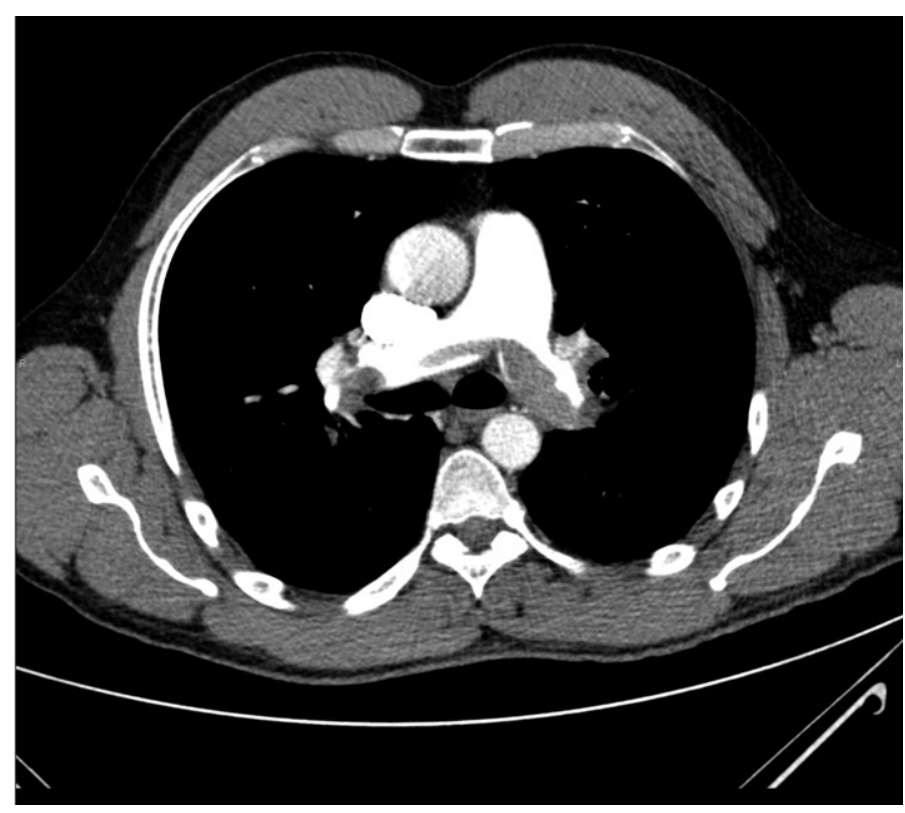

Figura 1.
En la exploración física resalta la disminución del murmullo vesicular en ambos campos pulmonares y de predominio en bases, así como la presencia de taquicardia (FC: $115 \mathrm{lpm})$.

Se realiza Eco-cardiograma mostrando dilatación de ventrículo derecho con disfunción moderada y compresión del tabique IV con IT leve. PSAP calculada de $70 \mathrm{mmHg}$.

Se realiza Angio-TAC de arterias pulmonares (Fig. 1 y 2).

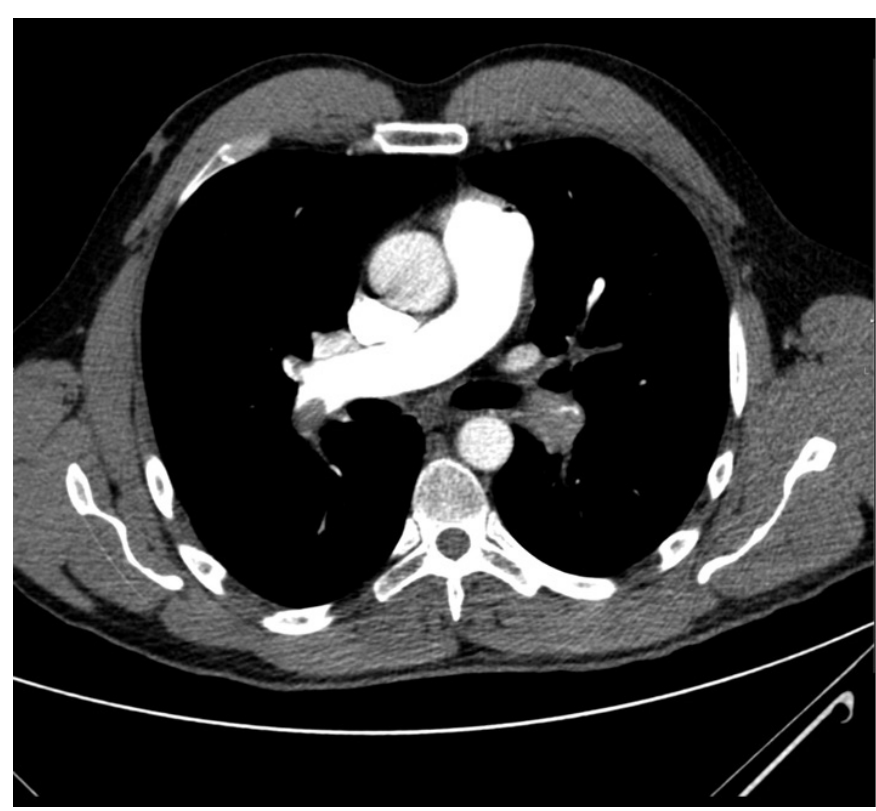

Figura 2.

${ }^{1}$ Cap. Médico. Servicio de Medicina Intensiva.

2 Tcol. Médico. Servicio de Medicina Intensiva.

${ }^{3}$ Tcol. Médico. Servicio de Radiodiagnóstico.

${ }^{4}$ Col. Médico. Servicio de Medicina Intensiva.

Hospital Central de la Defensa Gómez Ulla. Madrid. España.

Dirección para correspondencia: Pilar Borrego Jiménez. Servicio de Medicina Intensiva. Hospital Central de la Defensa Gómez Ulla. Glorieta del Ejército s/n. 28047. Madrid. España. pborjim@et.mde.es

Recibido: 13 de diciembre de 2011

Aceptado: 12 de marzo de 2012 


\section{Diagnóstico: Tromboembolismo pulmonar extenso, bilateral}

En el Angio-TAC de arterias pulmonares se observa: signos de tromboembolismo pulmonar extenso, bilateral, identificando múltiples imágenes de defecto de repleción en relación con material trombótico, en la bifurcación del tronco de la arteria pulmonar, en arterias lobares para ambos lóbulos superiores y sus ramas segmentarias, en arteria para la língula y para el LM, y en ambas arterias lobares inferiores, ramas segmentarias apicales y de la pirámide basal. Signos de hipertensión pulmonar con aumento del calibre del tronco de la arteria de pulmonar y de sus ramas derecha e izquierda, y dilata-

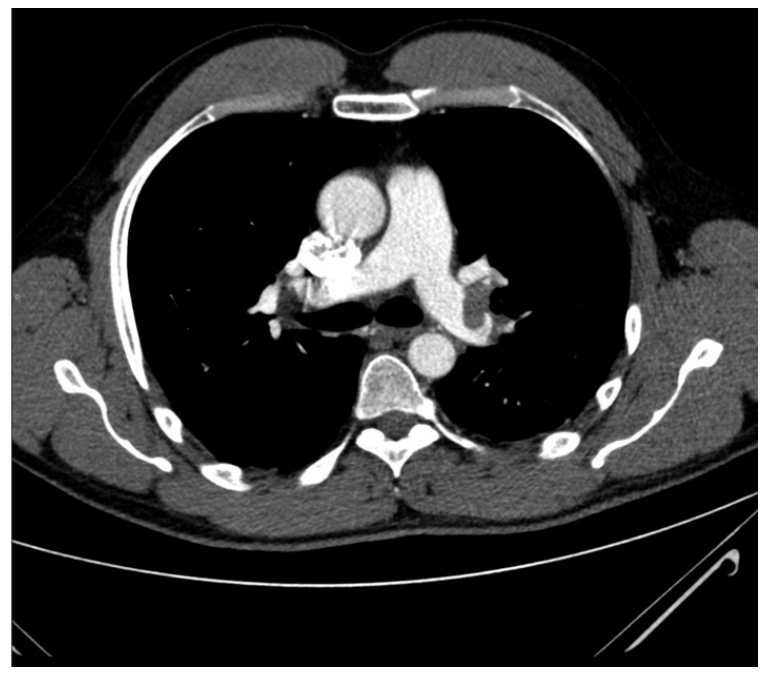

Figura 3.

\section{DISCUSIÓN}

La sospecha de un TEP está apoyada en la clínica, cuyos síntomas más característicos son la disnea, el dolor torácico o el síncope. En su estudio se incluye la realización de Eco-cardiograma, angio-TAC ${ }^{1}$, y determinación de marcadores de daño miocárdico (Pro-BNP y troponina). La gravedad del TEP se basa en la estimación del riesgo de muerte precoz (en los 30 días siguientes) según la presencia de marcadores de riesgo, incluidos en 3 grupos: clínicos (hipotensión y shock), marcadores de disfunción VD (valorado por Eco-cardiograma) y niveles de troponina.

En el caso de sospecha de TEP sin repercusión hemodinámica, en función de si la clínica del paciente es moderadamente compatible con el cuadro, se debe determinar D-dímero, y si éste es positivo, se recurrirá al TAC para confirmarlo. Si es negativo, o el TAC no muestra hallazgos compatibles, se descarta tratamiento. Si la clínica presenta alta compatibilidad, se debe realizar directamente un TAC, instaurando el tratamiento oportuno si las imágenes nos reafirman la sospecha diagnóstica.

Para el algoritmo diagnóstico de sospecha de TEP de alto riesgo deberá realizarse, en primer lugar, un TAC torácico, si la situación hemodinámica del paciente así lo permite. Si los hallazgos del TAC son compatibles con el diagnóstico de TEP, nos plantearemos el tratamiento más oportuno; si no es posible realizarlo, se deberá recurrir al Eco$\mathrm{CG}$, que si muestra una dilatación de VD también nos conducirá al diagnóstico de confirmación, considerando de nuevo el tratamiento.

El TEP masivo se correlaciona con el de alto riesgo, con los 3 grupos de marcadores de riesgo positivos $^{2}$. El tratamiento del TEP masivo ción del VD. En el segmento ápico-posterior de LSI se identifica área de aumento de densidad en vidrio deslustrado de morfología triangular subpleural en probable relación con infarto pulmonar. Se identifica otra área de aumento de densidad en vidrio deslustrado, mal definida, adyacente a cisura mayor derecha en el LSD en relación con infiltrado pulmonar. Cambios pleuroparenquimatosos en ambos vértices pulmonares de probable origen crónico. Ingresa en UCI para control y tratamiento, realizándose fibrinolisis con rtPA $\left(\right.$ Actilyse $\left.^{\circledR}\right)$.

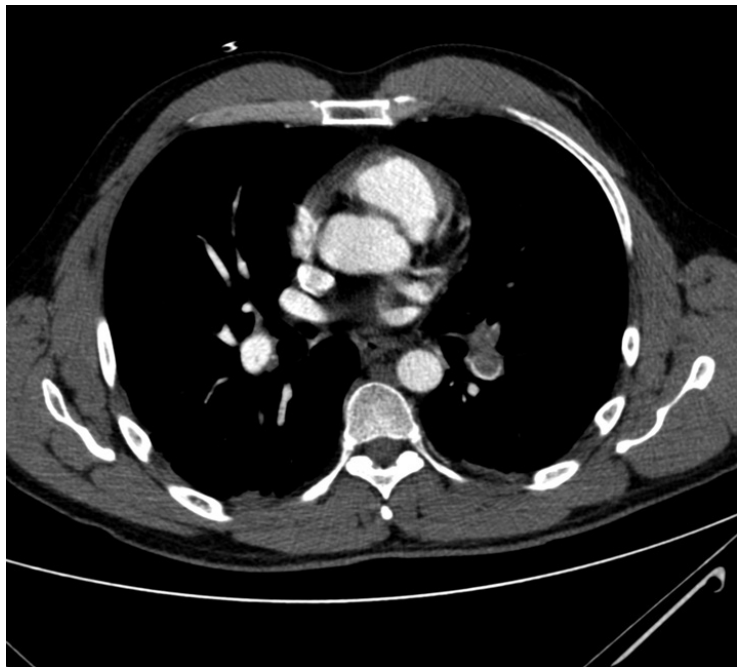

Figura 4.

con hipotensión, disfunción del VD y/o shock cardiogénico, incluye la utilización de fármacos fibrinolíticos (estreptoquinasa, urokinasa o rtPA), siempre que no existan contraindicaciones para su utilización (p.e.: hemorragia activa, antecedentes isquémicos recientes), asociados al empleo de anticoagulantes, con el riesgo que dichos fármacos conllevan, reseñando como complicación más frecuente la hemorragia intracraneal $^{3}$. Otras técnicas a considerar son: la embolectomía quirúrgica directa o la cateterización intervencionista, sobre todo en aquellos pacientes que presenten contraindicaciones a la fibrinólisis o cuando no se hayan conseguido resultados satisfactorios tras el empleo de la misma.

En el TEP submasivo (normotenso y sin evidencia de disfunción VD) debe realizarse una valoración riesgo-beneficio para el uso de fármacos fibrinolíticos, ya que su empleo no ha demostrado un aumento en la supervivencia ${ }^{4}$.

\section{BIBLIOGRAFÍA}

1. Perrier A, Howarth N, Didier D, et al. Performance of helical computed tomography in unselected outpatients with suspected pulmonary embolism. Ann Intern Med. 2001; 135: 88-97.

2. Torbicki et al. Guidelines on diagnosis and management of acute pulmonary embolism: the task force for diagnosis and management of acute pulmonary embolism of the European Society of Cardiology. Eur Heart J 2008; 29: 2276-2315.

3. Piazza G, Goldhaber SZ. Fibrinolysis for acute pulmonary embolism. Vasc Med 2010; 15 (5): 419-428.

4. Marshalls et al. Diagnosis and management of life-threatening pulmonary embolism. J. Intensive Care Med 2011.; 26 (5): 275-294. 